\title{
Acute kidney injury prevalence, progression and long-term outcomes in critically ill patients with COVID-19: a cohort study
}

\author{
Nuttha Lumlertgull 1,2,3, Leah Pirondini ${ }^{4}$, Enya Cooney ${ }^{1}$, Waisun Kok ${ }^{1}$, John Gregson ${ }^{4}$, Luigi Camporota ${ }^{1}$, \\ Katie Lane ${ }^{1}$, Richard Leach ${ }^{1}$ and Marlies Ostermann ${ }^{1 *}$
}

\begin{abstract}
Background: There are limited data on acute kidney injury (AKI) progression and long-term outcomes in critically ill patients with coronavirus disease-19 (COVID-19). We aimed to describe the prevalence and risk factors for development of AKI, its subsequent clinical course and AKI progression, as well as renal recovery or dialysis dependence and survival in this group of patients.
\end{abstract}

Methods: This was a retrospective observational study in an expanded tertiary care intensive care unit in London, United Kingdom. Critically ill patients admitted to ICU between 1st March 2020 and 31st July 2020 with confirmed SARS-COV2 infection were included. Analysis of baseline characteristics, organ support, COVID-19 associated therapies and their association with mortality and outcomes at 90 days was performed.

Results: Of 313 patients (70\% male, mean age $54.5 \pm 13.9$ years), 240 (76.7\%) developed AKI within 14 days after ICU admission: 63 (20.1\%) stage 1, 41 (13.1\%) stage 2, 136 (43.5\%) stage $3.113(36.1 \%)$ patients presented with AKI on ICU admission. Progression to AKI stage 2/3 occurred in 36\%. Risk factors for AKI progression were mechanical ventilation [HR (hazard ratio) 4.11; 95\% confidence interval (CI) 1.61-10.49] and positive fluid balance [HR 1.21 (95\% Cl 1.11-1.31)], while steroid therapy was associated with a reduction in AKI progression (HR 0.73 [95\% Cl 0.55-0.97]). Kidney replacement therapy (KRT) was initiated in 31.9\%. AKI patients had a higher 90 -day mortality than non-AKI patients (34\% vs. $14 \% ; p<0.001$ ). Dialysis dependence was $5 \%$ at hospital discharge and $4 \%$ at 90 days. Renal recovery was identified in $81.6 \%$ of survivors at discharge and in $90.9 \%$ at 90 days. At 3 months, $16 \%$ of all AKI survivors had chronic kidney disease (CKD); among those without renal recovery, the CKD incidence was 44\%.

Conclusions: During the first COVID-19 wave, AKI was highly prevalent among severely ill COVID-19 patients with a third progressing to severe AKI requiring KRT. The risk of developing CKD was high. This study identifies factors modifying AKI progression, including a potentially protective effect of steroid therapy. Recognition of risk factors and monitoring of renal function post-discharge might help guide future practice and follow-up management strategies. Trial registration NCT04445259

Keywords: COVID-19, SARS-CoV-2, Acute kidney injury, Kidney replacement therapy, Recovery, Dialysis, AKI

*Correspondence: marlies.ostermann@gstt.nhs.uk 1 Department of Critical Care, Guy's \& St Thomas' Hospital NHS Foundation Hospital, 249 Westminster Bridge Road, London SE1 7EH, UK Full list of author information is available at the end of the article

\section{Background}

Acute kidney injury (AKI) is prevalent in coronavirus disease-19 (COVID-19) patients. The pathogenesis is multifactorial including possible viral invasion, hypovolaemia, systemic inflammation, nephrotoxin exposure, endothelial dysfunction, coagulopathy, and organ crosstalk $[1,2]$. 
The incidence of AKI varies among geographical regions and clinical settings, ranging from 7 to $57 \%$ in hospitalised patients [3-5] and $19-80 \%$ in patients in the intensive care unit (ICU) [6-10]. Kidney replacement therapy (KRT) is utilised in 20-60\% [4, 11]. Both AKI and KRT are associated with adverse hospital outcomes and increased mortality [12].

Risk factors for AKI development include increased age, comorbidities, and racial background [13]. However, only few studies have examined the impact of COVID related therapies on risk of AKI progression [14] or longterm renal outcomes beyond hospital discharge in critically ill patients with COVID-19.

During the first wave of the COVID-19 pandemic, more than 10,000 patients were admitted to critical care in the United Kingdom (UK) [15]. Critical care bed capacity surged from 7.6 to 19.6 beds per 100,000 population [16]. The high prevalence of AKI and limited supply of consumables led to significant challenges and disruptions in KRT delivery [17, 18].

Understanding the burden of short- and longer-term complications is critical for prognostication, clinical management, and future resource planning. The aims of this study were to assess the AKI prevalence, trajectories, impact of COVID related therapies and longer-term renal outcomes following severe COVID-19.

\section{Materials and methods}

\section{Setting and Study design}

We retrospectively analysed all patients admitted to the ICU in a UK tertiary-level critical care unit during the first COVID wave at a time when critical care bed capacity had expanded from 64 to 160 beds.

\section{Participants}

All adult patients ( $\geq 18$ years old) who were admitted to ICU between 1st March and 31st July 2020 with a clinical diagnosis of COVID-19 following a confirmatory reverse transcriptase-polymerase chain reaction (RT-PCR) test of nasopharyngeal or endotracheal samples were included. We excluded (1) patients with pre-existing endstage kidney disease; (2) kidney transplant recipients, and (3) patients in whom COVID-19 was not the cause of ICU admission. If there were multiple admissions, only the first admission to ICU was included.

\section{Data collection}

Patient-level data (Additional file 1: Methods) were collected from the electronic health records through a combination of manual review by two independent trained data collectors and automated laboratory parameter extraction. Any disagreement was adjudicated by a third independent investigator.

\section{Outcomes}

The primary outcome was the incidence of AKI within 14 days after ICU admission. AKI was diagnosed and staged according to the Kidney Disease Improving Global Outcomes (KDIGO) criteria [19]. In brief, AKI is defined by an absolute increase in serum creatinine $(\mathrm{SCr})$ by $0.3 \mathrm{mg} / \mathrm{dL}(26.4 \mu \mathrm{mol} / \mathrm{L})$ within $48 \mathrm{~h}$ of ICU admission, an increase in $\mathrm{SCr} \geq 1.5$ times from baseline within 7 days, or urine output $<0.5 \mathrm{~mL} / \mathrm{kg} / \mathrm{h}$ for $\geq 6 \mathrm{~h}$. Both, $\mathrm{SCr}$ and urine output criteria were employed. Adjusted ideal body weight was used to calculate urine output per hour in obese patients [20]. Baseline SCr was determined from outpatient $\mathrm{SCr}$ values between 7 and 365 days before ICU admission. If a historical $\mathrm{SCr}$ result was not available, the first SCr on hospital admission [11] was used or SCr was determined by back-calculation using the Modification of Diet in Renal Disease (MDRD) formula and an assumed estimated glomerular filtration rate (eGFR) of $75 \mathrm{~mL} /$ $\mathrm{min} / 1.73 \mathrm{~m}^{2}$ [19]. Baseline AKI stage on admission and maximal AKI stage were reported. "AKI at ICU admission" was defined as any stage AKI present within $48 \mathrm{~h}$ of ICU admission [21]. AKI progression was defined as either new or worsening AKI to stage $2 / 3$ after $48 \mathrm{~h}$.

Secondary outcomes were KRT use during ICU stay, hospital mortality, 90-day mortality, dialysis dependence at hospital discharge and at 90 days, renal recovery at discharge and 90 days, and major adverse kidney events at 90 days (MAKE90). Renal recovery was defined as having $\mathrm{SCr}<1.5$ times of baseline and being dialysis independent at hospital discharge or at 90 days [22]. The composite outcome MAKE90 comprises of non-renal recovery, dialysis dependence, or death. $\mathrm{SCr}$ at 90 days was sought from the medical health records; if not available, the patient's general practitioner (GP) was contacted.

\section{Statistical analysis}

Baseline characteristics were summarised by the final AKI diagnosis. Baseline laboratory measurements used are the first values recorded within $24 \mathrm{~h}$ of ICU admission. Missing values were imputed using the most common category for categorical variables and the median value for continuous variables (Table 1). We performed 3 main analyses. First, we used logistic regression and forward stepwise selection ( $\mathrm{p}$-value threshold 0.05) to identify variables associated with AKI at ICU admission. We included the variables given in Table 1 as candidate covariates, except for variables included in the definition of AKI ( $\mathrm{SCr}$, urine output) and variables representing frailty indices (APACHE II, Charlson Comorbidity Index (CCI) and Clinical Frailty Score (CFS)). Second, we examined risk factors for progression to stage 2/3 AKI after ICU admission. For this, we excluded patients with AKI 
Table 1 Baseline characteristics of patients and final acute kidney injury status

\begin{tabular}{|c|c|c|c|}
\hline Characteristics & $\begin{array}{l}\text { Overall } \\
\mathrm{n}=313^{\mathrm{a}}\end{array}$ & $\begin{array}{l}\text { No AKI } \\
\mathrm{n}=73^{\mathrm{a}}\end{array}$ & $\begin{array}{l}\text { AKI } \\
n=240^{a}\end{array}$ \\
\hline Age (years) & $54.5(13.9)$ & $51.6(13.8)$ & $55.4(13.9)$ \\
\hline Male sex & $219(70 \%)$ & $49(67 \%)$ & $170(71 \%)$ \\
\hline Ethnicity: White & $119(46 \%)$ & $25(42 \%)$ & $94(47 \%)$ \\
\hline Black & $90(35 \%)$ & $16(27 \%)$ & $74(37 \%)$ \\
\hline Others & 49 (19\%) & $18(31 \%)$ & $31(16 \%)$ \\
\hline Admission: ED & $94(30 \%)$ & $18(25 \%)$ & $76(32 \%)$ \\
\hline Ward & $102(33 \%)$ & $24(33 \%)$ & $78(32 \%)$ \\
\hline Transfer from other ICUs & $114(36 \%)$ & $31(42 \%)$ & $83(35 \%)$ \\
\hline Others & $3(1.0 \%)$ & $0(0 \%)$ & $3(1.2 \%)$ \\
\hline Infection setting: Community-acquired & $275(90 \%)$ & $61(85 \%)$ & $214(91 \%)$ \\
\hline Hospital acquired & $8(2.6 \%)$ & $1(1.4 \%)$ & $7(3.0 \%)$ \\
\hline Occupational & $24(7.8 \%)$ & $10(14 \%)$ & $14(6.0 \%)$ \\
\hline $\mathrm{BMI}\left(\mathrm{kg} / \mathrm{m}^{2}\right)$ & $29.6(6.5)$ & $27.9(5.2)$ & $30.1(6.7)$ \\
\hline Current smoker & $13(6.1 \%)$ & $6(11 \%)$ & $7(4.3 \%)$ \\
\hline Admission SOFA score & $5.4(2.6)$ & $3.9(2.3)$ & $5.9(2.5)$ \\
\hline APACHE II Score & $14.2(4.8)$ & $12.5(4.8)$ & $14.7(4.7)$ \\
\hline Clinical frailty score & $2.6(1.0)$ & $2.4(0.9)$ & $2.6(1.0)$ \\
\hline Comorbidities: diabetes & $95(30 \%)$ & $12(16 \%)$ & $83(35 \%)$ \\
\hline Asthma & $48(15 \%)$ & $14(19 \%)$ & $34(14 \%)$ \\
\hline Hypertension & $126(40 \%)$ & $19(26 \%)$ & $107(45 \%)$ \\
\hline Coronary artery disease & $15(4.8 \%)$ & $2(2.7 \%)$ & $13(5.4 \%)$ \\
\hline Congestive heart failure & $14(4.5 \%)$ & $2(2.7 \%)$ & $12(5.0 \%)$ \\
\hline Atrial fibrillation/atrial flutter & $11(3.5 \%)$ & $1(1.4 \%)$ & $10(4.2 \%)$ \\
\hline COPD & $12(3.8 \%)$ & $0(0 \%)$ & $12(5.0 \%)$ \\
\hline Chronic kidney disease & $22(7.0 \%)$ & $1(1.4 \%)$ & $21(8.8 \%)$ \\
\hline Chronic liver disease & $12(3.8 \%)$ & $1(1.4 \%)$ & $11(4.6 \%)$ \\
\hline HIV infection & $7(2.2 \%)$ & $3(4.1 \%)$ & $4(1.7 \%)$ \\
\hline Malignancy & $14(4.5 \%)$ & $3(4.1 \%)$ & $11(4.6 \%)$ \\
\hline Other coinfections & $42(13 \%)$ & $9(12 \%)$ & $33(14 \%)$ \\
\hline Charlson Comorbidity Index & $0.8(1.3)$ & $0.6(1.2)$ & $0.9(1.3)$ \\
\hline \multicolumn{4}{|l|}{ Type of ventilation on admission: } \\
\hline Invasive & $254(81.2 \%)$ & $48(65.8 \%)$ & $206(85.8 \%)$ \\
\hline Non-invasive & $4(1.3 \%)$ & 0 & $4(1.7 \%)$ \\
\hline High-flow nasal cannula & $21(6.7 \%)$ & $8(11.0 \%)$ & $13(5.4 \%)$ \\
\hline None & $34(10.9 \%)$ & $17(23.3 \%)$ & $17(7.1 \%)$ \\
\hline Vasopressor support on admission & $133(42.5 \%)$ & $23(31.5 \%)$ & $110(45.8 \%)$ \\
\hline ECMO & $58(18.5 \%)$ & $18(24.7 \%)$ & $40(16.7 \%)$ \\
\hline Medications: ACE-Inhibitor & $54(17 \%)$ & $8(11 \%)$ & $46(19 \%)$ \\
\hline ARB & $39(12 \%)$ & $5(6.8 \%)$ & $34(14 \%)$ \\
\hline Baseline creatinine ${ }^{b}$ & $86.2(38.7)$ & $73.7(31.7)$ & $90.0(39.9)$ \\
\hline $\mathrm{pH}$ & $7.4(0.1)$ & $7.4(0.1)$ & $7.4(0.1)$ \\
\hline $\mathrm{PaO}_{2}(\mathrm{kPa})$ & $11.6(5.0)$ & $11.7(5.1)$ & $11.5(5.0)$ \\
\hline lonised calcium (mmol/L) & $1.1(0.1)$ & $1.1(0.1)$ & $1.1(0.1)$ \\
\hline Lactate $(\mathrm{mmol} / \mathrm{L})$ & $2.2(2.0)$ & $1.9(1.8)$ & $2.2(2.0)$ \\
\hline Chloride (mEq/L) & $99.8(5.7)$ & $99.5(6.4)$ & $99.9(5.5)$ \\
\hline White blood cells $(10 \wedge 9 / L)$ & $9.9(4.8)$ & $9.7(5.2)$ & $9.9(4.6)$ \\
\hline Neutrophils $(10 \wedge 9 / L)$ & $8.4(4.4)$ & $8.4(4.7)$ & $8.4(4.3)$ \\
\hline Lymphocytes (10^9/L) & $0.8(0.5)$ & $0.9(0.4)$ & $0.8(0.6)$ \\
\hline Haemoglobin (g/L) & $115.8(22.1)$ & $114.4(24.5)$ & $116.2(21.3)$ \\
\hline
\end{tabular}


Table 1 (continued)

\begin{tabular}{|c|c|c|c|}
\hline Characteristics & $\begin{array}{l}\text { Overall } \\
\mathrm{n}=313^{\mathrm{a}}\end{array}$ & $\begin{array}{l}\text { No AKI } \\
n=73^{a}\end{array}$ & $\begin{array}{l}\text { AKI } \\
n=240^{a}\end{array}$ \\
\hline Platelet $(10 \wedge 9 / \mathrm{L})$ & $253.2(108.7)$ & $284.1(128.8)$ & $243.8(100.3)$ \\
\hline Urea (mmol/L) & $10.1(9.4)$ & $6.7(4.3)$ & $11.0(10.2)$ \\
\hline Creatinine $(\mu \mathrm{mol} / \mathrm{L})$ & $121.0(101.7)$ & $70.4(30.7)$ & $136.4(110.4)$ \\
\hline Albumin (g/L) & $31.2(6.4)$ & $31.1(6.3)$ & $31.2(6.4)$ \\
\hline $\operatorname{ALT}(U / L)$ & $67.2(115.7)$ & $49.8(41.9)$ & $72.4(129.2)$ \\
\hline Bilirubin ( $\mathrm{mmol} / \mathrm{L})$ & $12.8(16.3)$ & $9.4(5.8)$ & $13.7(18.2)$ \\
\hline CRP (mg/L) & $203.6(137.3)$ & $166.9(129.7)$ & $214.9(137.8)$ \\
\hline Sodium (mmol/L) & $138.5(6.3)$ & $139.3(6.6)$ & $138.3(6.2)$ \\
\hline Potassium (mmol/L) & $4.5(0.8)$ & $4.3(0.7)$ & $4.6(0.9)$ \\
\hline Bicarbonate (mmol/L) & $24.5(5.5)$ & $26.9(6.6)$ & $23.8(5.0)$ \\
\hline Fibrinogen (g/L) & $6.8(2.0)$ & $6.7(1.9)$ & $6.8(2.1)$ \\
\hline Ferritin (ng/mL) & $1,991.3(2,672.8)$ & $1,332.2(1,233.7)$ & 2,199.1 (2,958.3) \\
\hline $\mathrm{PaO}_{2} / \mathrm{FiO}_{2}, \mathrm{kPa}$ & $21.0(12.5)$ & $23.3(11.9)$ & $20.4(12.6)$ \\
\hline Urine output (ml) & 1,078.0 (818.5) & 1,289.9 (787.0) & 1,014.1 (818.6) \\
\hline \multicolumn{4}{|c|}{ a Statistics presented: mean (SD); $n(\%)$} \\
\hline \multicolumn{4}{|c|}{${ }^{\mathrm{b}}$ Determined at true baseline creatinine $(n=106)$, first hospital admission $(n=130)$ or baseline creatinine back calculated by MDRD formula $(n=77)$} \\
\hline \multicolumn{4}{|c|}{ Missing: ethnicity $(n=55)$, infection setting $(n=6)$, smoker $(n=99)$, homeless $(n=10)$, BMI $(n=33)$} \\
\hline \multicolumn{4}{|c|}{$\begin{array}{l}\text { Missing: } \mathrm{pH}(n=1), \mathrm{PaO}_{2}(n=8) \text {, ionised calcium }(n=3) \text {, lactate }(n=1) \text {, chloride }(n=6) \text {, white blood cells }(n=5) \text {, neutrophils }(n=24) \text {, lymphocytes }(n=5) \text {, Hb }(n=5) \text {, } \\
\text { platelet }(n=5) \text {, urea }(n=17) \text {, creatinine }(n=4) \text {, albumin }(n=4), \operatorname{ALT}(n=9) \text {, bilirubin }(n=10), \mathrm{CRP}(n=7) \text {, sodium }(n=3) \text {, potassium }(n=4) \text {, bicarbonate }(n=3) \text {, } \\
\text { fibrinogen }(n=35) \text {, ferritin }(n=46), \mathrm{PaO}_{2} / \mathrm{FiO}_{2} \text { ratio }(n=9) \text {, urine output }(n=2)\end{array}$} \\
\hline \multicolumn{4}{|c|}{$\begin{array}{l}C O P D \text { chronic obstructive pulmonary disease, } E D \text { emergency department, } H I V \text { human immunodeficiency virus, SOFA Sequential Organ Failure Assessment, } A P A C H E ~ I I \\
\text { Acute Physiologic and Chronic Health Evaluation II, } A C E \text { angiotensin-converting enzyme, } A R B \text { angiotensin receptor blocker, } A L T \text { alanine transaminase, } C R P C \text {-reactive } \\
\text { protein, ECMO extracorporeal membrane oxygenation, } B M I \text { body mass index, } k P a \text { kiloPascal }\end{array}$} \\
\hline
\end{tabular}

stage 2/3 diagnosed within $48 \mathrm{~h}$ from ICU admission. Cox proportional hazards models with forward stepwise selection ( $p$-value threshold 0.05 ) was used. Hazard ratios (HRs) for ICU-related treatments or complications adjusted for baseline predictors of AKI progression were calculated. We used time-updated covariates to model ICU-related treatments and complications. Patients were censored at whichever of the following occurred first: AKI progression, death, or 90-day from ICU admission. Six patients were censored between 74 and 87 days due to database lock. Finally, we compared 90-day mortality according to maximal AKI stage using Kaplan-Meier curves. We calculated HRs for mortality according to time-updated maximal AKI stage. We additionally examined predictors of 90-day mortality using the same methods as applied to examine predictors of AKI progression. Analyses were conducted with $\mathrm{R}$ version 3.6.1.

\section{Results}

Between 1st March and 31st July 2020, 335 critically ill COVID-19 positive patients were admitted to Critical Care (Additional file 1: Figure S1) of whom 313 patients were included in the final analysis [70\% male, mean age 54.5 standard deviation (SD) 13.9 years]. The mean APACHE II score and SOFA score were $14.2 \pm 4.8$ and $5.4 \pm 2.6$, respectively; $81.2 \%$ patients received invasive mechanical ventilation, $42.5 \%$ patients received vasopressor support, and $18.5 \%$ received veno-venous ECMO on admission. Baseline characteristics and laboratory data by final AKI diagnosis are shown in Table 1.

\section{AKI diagnosis and staging}

AKI was present in 240 (76.7\%) patients throughout ICU stay of whom $20.1 \%$ had AKI stage $1,13.1 \%$ stage 2 , and 43.5\% stage 3 (Additional file 1: Table S1). SCr criteria alone accounted for $22.5 \%$, urine output criteria alone for $16.3 \%$, and both criteria defined $61.3 \%$ of patients as having AKI. True baseline SCr was available for 35.8\% patients.

\section{AKI at ICU admission}

Among all AKI patients, 76\% had AKI within $48 \mathrm{~h}$ of ICU admission. Risk factors included age, higher BMI, lower serum bicarbonate, lower platelet count, higher C-reactive protein (CRP), and higher serum lactate (Table 2).

\section{AKI progression}

115 (36.7\%) patients progressed to AKI stage 2/3 after $48 \mathrm{~h}$ (Additional file 1: Table S1). Among procedures and complications during ICU stay, invasive mechanical ventilation [adjusted hazard ratios (aHR) 4.11, 95\% CI 1.61-10.49] and positive cumulative fluid balance in the 
Table 2 Baseline predictors of any stage AKI at ICU admission

\begin{tabular}{llll}
\hline Characteristic & Odds ratio & $\mathbf{9 5 \%} \mathbf{C l}$ & p-value \\
\hline Age & 1.02 & $1.00,1.04$ & 0.024 \\
Female sex & 1.09 & $0.61,1.96$ & 0.771 \\
BMI $\left(\mathrm{kg} / \mathrm{m}^{2}\right)$ & 1.05 & $1.01,1.10$ & 0.019 \\
Ethnicity & & & \\
Not Black & Ref & Ref & \\
Black & 1.66 & $0.97,2.88$ & 0.066 \\
Lower baseline HCO $_{3}{ }^{a}$ & 1.07 & $1.02,1.13$ & 0.006 \\
Lower baseline platelet $^{\mathrm{b}}$ & 1.34 & $1.05,1.73$ & 0.020 \\
Baseline CRP $^{\mathrm{C}}$ & 1.28 & $1.06,1.57$ & 0.013 \\
Lower baseline haemoglobin $^{\mathrm{d}}$ & 1.13 & $1.00,1.29$ & 0.059 \\
Baseline potassium $^{\mathrm{e}}$ & 1.39 & $1.00,1.95$ & 0.051 \\
Baseline lactate $^{\mathrm{e}}$ & 1.31 & $1.11,1.61$ & 0.005 \\
\hline
\end{tabular}

a per $\mathrm{mEg} / \mathrm{L}$

b $\operatorname{per} 10^{11} / \mathrm{L}$

c per $100 \mathrm{mg} / \mathrm{L}$

${ }^{d}$ per $10 \mathrm{~g} / \mathrm{L}$

e per $\mathrm{mmol} / \mathrm{L}$

$B M I$ body mass index, $C R P C$-reactive protein

first 48 h (aHR 1.21, 95\% CI 1.11-1.31), were independent risk factors, whilst new steroid use was associated with a reduced risk of AKI progression [aHR 0.73, 95\%CI 0.55-0.97]. Treatment with ECMO, proning, remdesivir and anticoagulation use were not independently associated with AKI progression (Table 3).

\section{Kidney replacement therapy (KRT)}

One-hundred patients $(32 \%)$ received KRT during ICU stay. Among them, the median time to KRT was 3 days (IQR 1-6) from ICU admission with a median KRT duration of 12 days (IQR 6-22). The initial modality was continuous kidney replacement therapy (CKRT) in 87 patients, prolonged intermittent kidney replacement therapy (PIKRT) in 12 patients, and intermittent haemodialysis (IHD) in 1 patient. The primary indications for KRT were hyperkalaemia $(n=37)$, oliguria $(n=67)$, acidosis $(n=25)$, high urea $(n=73)$, pulmonary oedema $(n=12)$, and others $(n=15$, including rhabdomyolysis, fluid and electrolyte imbalances).

\section{ICU outcomes and 90-day mortality}

Overall ICU mortality of the total cohort was $28 \%$; $33 \%$ in AKI patients vs $12 \%$ in non-AKI patients, $p<0.001$. The 90 -day mortality was $29 \%$; $34 \%$ in AKI versus $14 \%$ in nonAKI patients $(p<0.001)$ (Table 4$)$. The HRs for final AKI stage 1,2 , and 3 for 90-day mortality versus no AKI were 2.52 (95\% CI 1.11-5.72; $p=0.03$ ), 11.1 (95\% CI 5.1923.8; $p<0.001$ ), and 5.79 (95\% CI 3.49-9.61; $p<0.001$ ), respectively. The Kaplan-Meier curves for maximal AKI staging are shown in Fig. 1.

We identified several factors present on ICU admission that were independently associated with increased 90-day mortality risk: age (HR 1.04; 95\% CI 1.03-1.06), male sex (HR 2.17; 95\% CI 1.28-3.68), asthma (HR 1.84; 95\% CI 1.06-3.19), atrial flutter or fibrillation (HR 2.95; 95\% CI 1.10-7.90), high serum lactate (HR 1.25; 95\% CI 1.13-1.39), neutrophilia (HR 1.07; 95\% CI 1.01-1.13); lower lymphocyte count (HR 2.31; 95\% CI 1.32-4.04), lower $\mathrm{PaO}_{2} / \mathrm{FiO}_{2}$ ratio (HR 1.95; 95\% CI 1.26-2.98) and lower pH (HR 1.30; 95\% CI 1.00-1.69) (Additional file 1: Table S3). With regard to ICU treatments and complications, KRT use, vasopressor support, prone position, and ARDS were independent risk factors for mortality, with aHR 1.69 (95\%CI 1.05-2.72), 3.00 (95\%CI 1.54-5.86), 1.44 (1.08-1.92), and $2.20(1.38-3.51)$, respectively (Additional file 1: Table S4).

\section{ICU and 90-day renal outcomes and recovery}

At hospital discharge, 8 of 222 survivors (4\%) were dialysis dependent, and $81.6 \%$ of survivors had full renal recovery. At 90 days, 9 of 197 survivors (5\%) with available data were dialysis dependent. SCr was available in 194 (87.8\%) survivors; of whom $90.9 \%$ had renal recovery. MAKE90 occurred in $42.4 \%$ of all patients. (Additional file 1: Table S5) Of all AKI survivors, 16.5\% had CKD (eGFR $<60 \mathrm{ml} / \mathrm{min} / 1.73 \mathrm{~m} 2$ ) at 90 days, comprising $44.8 \%$ of patients who did not recover renal function at discharge compared with $10.1 \%$ of those with renal recovery at discharge, respectively (Additional file 1: Table S6). Figure 2 shows temporal changes in $\mathrm{SCr}$ from baseline, maximum, at hospital discharge, and at 90 days in survivors with $\mathrm{SCr}$ results available. Compared with baseline SCr, AKI survivors without renal recovery at discharge had higher $\mathrm{SCr}$ values at 90 days, while AKI survivors who recovered renal function had lower $\mathrm{SCr}$ results; patients without AKI did not have significant changes in SCr post-discharge (Additional file 1: Table S7).

The relationship between final AKI stage and duration is shown in Additional file 1: Table S6. AKI duration was categorised as prolonged ( $\geq 7$ days or non-recovery) in $37.1 \%$, sustained (3-6 days) in $12.8 \%$, and transient ( $\leq 2$ days) in $26.8 \%$, respectively. Prolonged AKI and non-recovery were more frequent in those with final AKI stage 3.

\section{Discussion}

Our data confirm the high prevalence of AKI in critically ill COVID-19 patients during the first wave. Most patients developed AKI stage 3, about one-third of patients received KRT, and the majority of AKI occurred within $48 \mathrm{~h}$ of ICU admission. It is the first study which 
Table 3 Adjusted* hazard ratios for acute kidney injury progression in intensive care unit according to therapies

\begin{tabular}{|c|c|c|c|c|c|}
\hline Variable & $\begin{array}{l}\text { Patients with AKI } \\
\text { progression }\end{array}$ & $\begin{array}{l}\text { Patients with no AKI } \\
\text { progression }\end{array}$ & Hazard ratio & $95 \% \mathrm{Cl}$ & P-value \\
\hline Cumulative net balance at $48 \mathrm{~h}$ (each $1000 \mathrm{ml}$ ) & & & 1.205 & $1.108,1.311$ & $<0.001$ \\
\hline \multicolumn{6}{|l|}{ Ventilation type } \\
\hline None & 5 & 26 & 1 (ref) & & \\
\hline Invasive & 89 & 100 & 4.114 & $1.614,10.485$ & 0.003 \\
\hline Non-invasive/mask/HFNC & 6 & 14 & 2.677 & $0.783,9.150$ & 0.116 \\
\hline \multicolumn{6}{|l|}{ Vasopressor } \\
\hline No & 51 & 94 & 1 (ref) & & \\
\hline Yes & 49 & 46 & 1.355 & $0.906,2.025$ & 0.139 \\
\hline \multicolumn{6}{|l|}{ ECMO } \\
\hline No & 88 & 112 & 1 (ref) & & \\
\hline Yes & 12 & 28 & 0.808 & $0.411,1.590$ & 0.538 \\
\hline \multicolumn{6}{|l|}{ Prone position } \\
\hline No & 50 & 100 & 1 (ref) & & \\
\hline Yes & 50 & 40 & 0.926 & $0.671,1.279$ & 0.642 \\
\hline \multicolumn{6}{|l|}{ Remdesivir } \\
\hline No & 98 & 131 & 1 (ref) & & \\
\hline Yes & 2 & 9 & 0.407 & $0.055,2.985$ & 0.376 \\
\hline \multicolumn{6}{|l|}{ New steroids } \\
\hline No & 28 & 71 & 1 (ref) & & \\
\hline Yes & 72 & 69 & 0.730 & $0.550,0.970$ & 0.030 \\
\hline \multicolumn{6}{|l|}{$\begin{array}{l}\text { Anticoagulation use (excluding thromboembolism } \\
\text { prophylaxis) }\end{array}$} \\
\hline No & 47 & 92 & 1 (ref) & & \\
\hline Yes & 53 & 48 & 0.833 & $0.580,1.196$ & 0.322 \\
\hline Total & 100 & 140 & & & \\
\hline
\end{tabular}

* adjustment for age, sex, and the following factors measured at ICU admission: $\mathrm{AKI}_{\text {stage, }} \mathrm{HCO}_{3}{ }^{-}$, bilirubin, $\mathrm{ALT}, \mathrm{iCa}, \mathrm{PaO}_{2} / \mathrm{FiO}{ }_{2}$ ratio, $\mathrm{BMI}$ and $\mathrm{Charlson} \mathrm{Comorbidity}$ Index

HFNC, high-flow nasal cannula; ECMO, extracorporeal membrane oxygenation; AKI, acute kidney injury; Cl, confidence interval

highlights the high risk of progressive AKI after $48 \mathrm{~h}$ (36\%) in COVID-19 and identifies potentially modifiable risk factors. Although mortality was high in AKI patients, less than $5 \%$ of survivors were dialysis dependent at 90 days. However, the considerable risk of CKD at 90 days should be appreciated, especially in patients without renal recovery at hospital discharge.

The high incidence of AKI in our study compared with other studies $[6,10,23-25]$ might have several explanations. First, most patients required multi-organ support, including mechanical ventilation $(81 \%)$, vasopressor support (43\%), and ECMO (19\%). One-third of patients were referred from other institutions for specialist input or as part of mutual aid during the pandemic. A third were admitted from general medical wards which might reflect AKI onset during hospitalisation before ICU admission. Second, we employed both $\mathrm{SCr}$ and urine output criteria to define AKI, where other studies only used $\mathrm{SCr}$ results. $16 \%$ of cases were identified by urine output criteria alone. Finally, there might have been stricter admission criteria to ICU, given the pandemic and the relatively low number of ICU beds in the UK $[7,26]$.

Patients presenting with AKI at ICU admission were generally older, had a higher body mass index, and were more acutely ill as evidenced by lower bicarbonate, lower platelet, higher lactate, and higher CRP. As suggested by other studies, this suggests that AKI is a marker of disease severity, and that inflammation might contribute to AKI development [8, 9, 27, 28]. Onethird of all patients progressed to moderate or severe AKI after $48 \mathrm{~h}$ in ICU. A previous study revealed that $15 \%$ of patients had AKI stage $\geq 2$ on admission and $60 \%$ progressed from stage 2 to 3 or needed KRT afterwards [29]. Similar to non-COVID-19 patients, positive fluid balance in the first $48 \mathrm{~h}$ after ICU admission was associated with AKI progression [30-32]. As in previous reports, invasive mechanical ventilation increased the risk of AKI by about fourfold [5, 10, 33-35]. The use of KRT in our cohort was similar to reports from other 
Table 4 Key outcomes by final acute kidney injury status

\begin{tabular}{|c|c|c|c|c|}
\hline & Overall & Non-AKI & AKI & P value \\
\hline Outcome & $(n=313)$ & $(n=73)$ & $(n=240)$ & \\
\hline Kidney replacement therapy use in ICU & $100(32 \%)$ & $1(1 \%)$ & $99(41 \%)$ & $<0.001^{\mathrm{a}}$ \\
\hline 90-day mortality ${ }^{b}$ & $92(29 \%)$ & $10(14 \%)$ & $82(34 \%)$ & $<0.001^{c}$ \\
\hline \multicolumn{5}{|c|}{ Dialysis dependence at hospital discharge (in survivors) } \\
\hline No & $214(96 \%)$ & $64(100 \%)$ & $150(95 \%)$ & \\
\hline Yes & $8(4 \%)$ & $0(0 \%)$ & $8(5 \%)$ & $0.109^{a}$ \\
\hline \multicolumn{5}{|l|}{ Dialysis dependence at 90 days (in survivors) } \\
\hline No & $188(95 \%)$ & $50(94 \%)$ & $138(96 \%)$ & \\
\hline Yes & $9(5 \%)$ & $3(6 \%)$ & $6(4 \%)$ & $0.704^{a}$ \\
\hline (Missing) & 24 & 10 & 14 & \\
\hline Renal recovery at discharge ${ }^{d}$ & N/A & $\mathrm{N} / \mathrm{A}$ & $129 / 158(81.6 \%)$ & - \\
\hline Renal recovery at 90 days ${ }^{e}$ & N/A & N/A & $130 / 143(90.9 \%)$ & - \\
\hline
\end{tabular}

AKI, acute kidney injury; ICU, intensive care unit

a P-value calculated from Fisher's exact test

b 88 patients died in ICU, 4 patients died outside of ICU ( 3 in hospital, 1 after hospital discharge)

c P-value calculated from a Cox proportional hazards model using time-updated AKI diagnosis as covariate

${ }^{d}$ Recovery at discharge is defined as having serum creatinine of $<1.5$ times of baseline or being dialysis independent at discharge (within the population of survivors only)

e Recovery at 90 days is defined as having serum creatinine of $<1.5$ times of baseline or being dialysis independent at discharge (within the population of survivors only). Note there are 27 missing observations

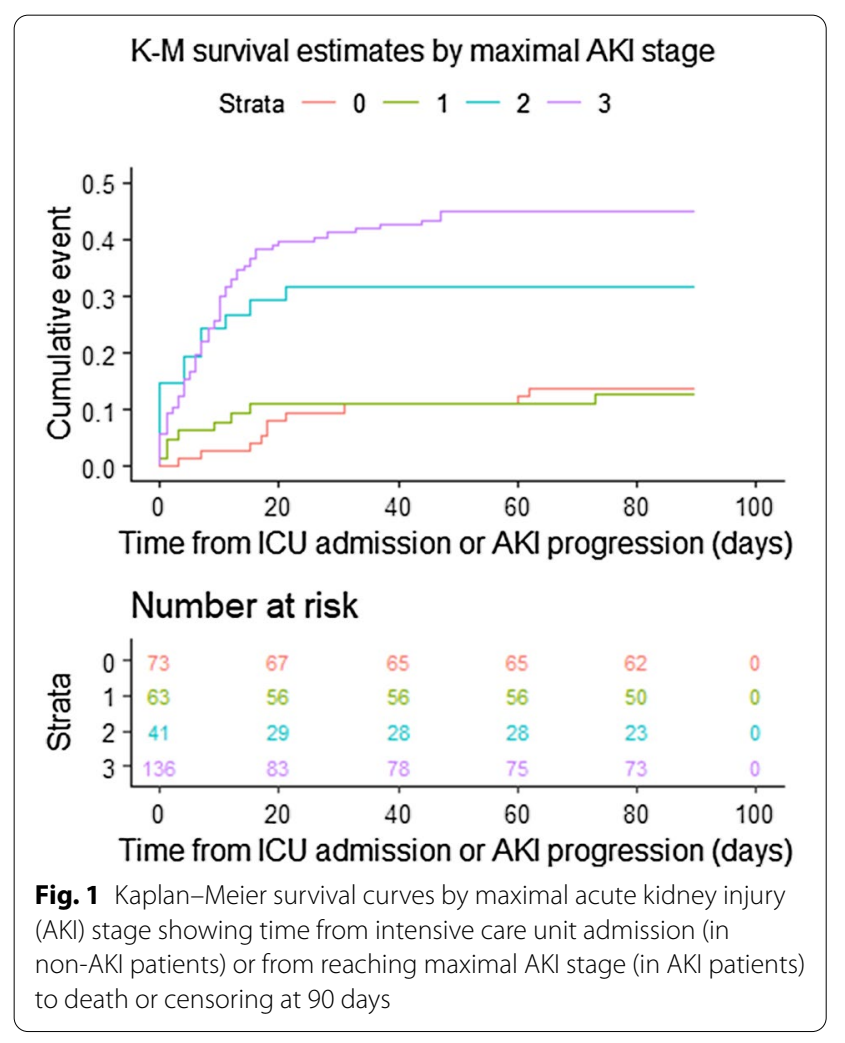

institutions and national UK data [11, 15], and our association between AKI stage and mortality was also in keeping with other studies $[12,36]$.

This study included critically ill individuals admitted to critical care during the UK's first wave of the pandemic. Effective management strategies were unknown during this time. In the following months, randomised controlled trials identified systemic steroid use as an effective COVID-19 therapy [37, 38]. Our results showed for the first time that steroid use was associated with a reduced risk of AKI progression. However, indications for treatment initiation and dosage were not protocolised and left to the clinicians' discretion at the time. Consequently, indication bias and residual confounding effects cannot be excluded. Also, the exact protective mechanism is not clear from our analysis. We note that renal outcomes were not reported in the RECOVERY trial [38]. At this stage, our results of steroid therapy being protective on renal outcomes should be viewed as hypothesis-generating to guide future adequately powered studies [29].

Proning was associated with higher mortality, which may reflect the severity of COVID-19 rather than the effects of proning on mortality itself [39]. The overall mortality rate was relatively low compared with previous studies comprising patients with similar severity and receiving mechanical ventilation $[7,8,23,40]$. Possible explanations are younger age and relatively low CCI and CFS. Other reasons may include factors 


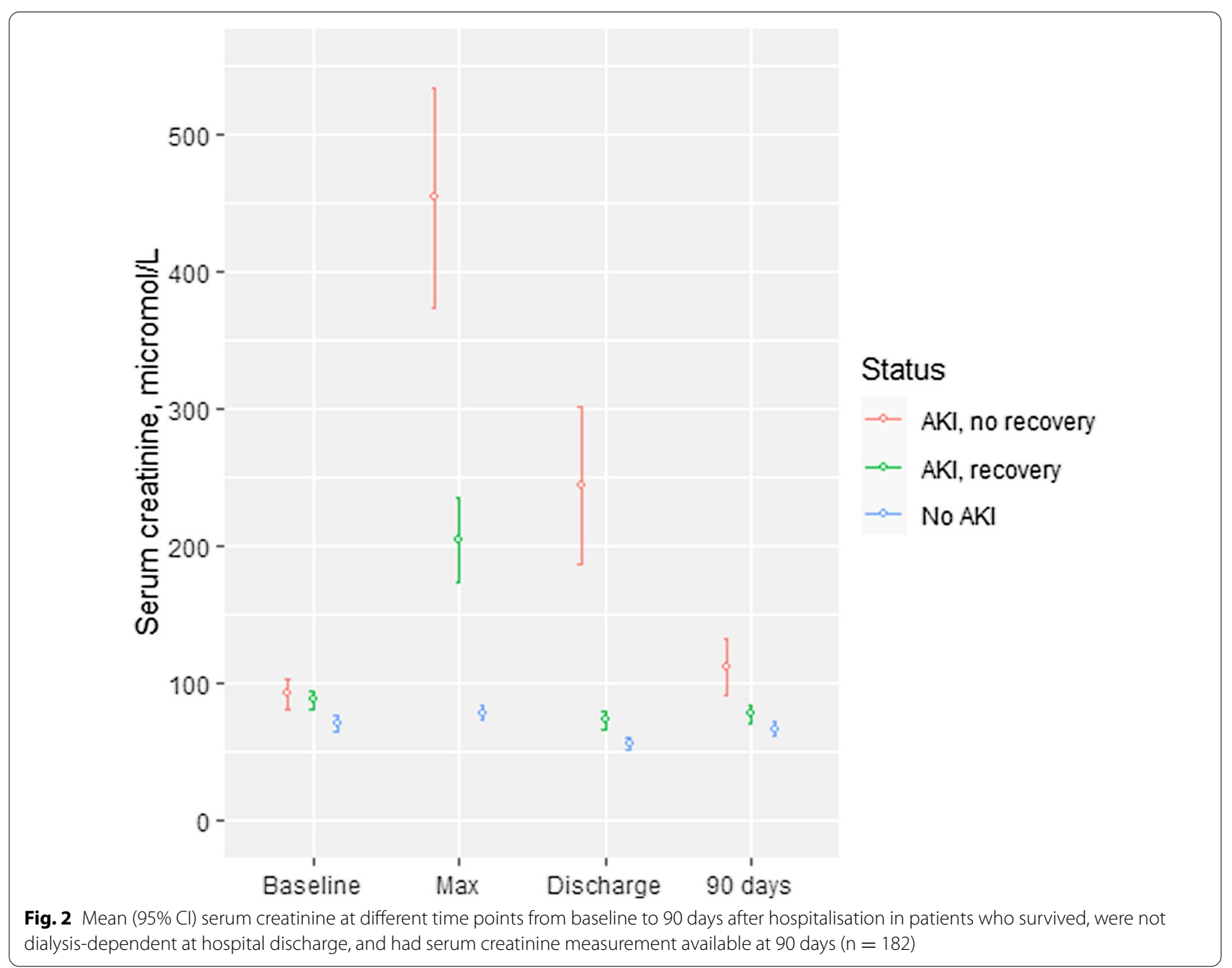

directly related to the pandemic, i.e. changes to ICU organisation, staffing and resource utilisation, and variations in clinical practice that are not captured here.

Renal recovery after AKI is important for patients, families, and all stakeholders involved. Our study shows a $82 \%$ recovery rate at hospital discharge based on $\mathrm{SCr}$ results and at 90 days with $<5 \%$ of patients being dialysis dependent. Other investigations reported renal recovery rates between 17 and $84 \%$ and dialysis dependence rates between 8 and 56.5\% [11, 18, 41-46]. Our low dialysis dependence rates perhaps may be due to a relatively low proportion of patients with pre-existing CKD. However, loss of muscle mass during critical illness results in a decline in creatinine generation which may lead to an overestimation of renal function as illustrated by our data $[47,48]$. Patients with COVID-19 who did not have AKI or had recovered renal function after AKI had a lower $\mathrm{SCr}$ at discharge compared to baseline. Our analysis also highlights the significant risk of CKD after
COVID-associated AKI: $16 \%$ of all AKI survivors had $\mathrm{CKD}$ at 3 months. Among those without renal recovery, the incidence was increased to $44 \%$. This is in line with a recent studies showing a fast rate of GFR decline postAKI [49-51]. If confirmed in future studies, this might pose a significant post-pandemic healthcare and KRT burden which warrants further evaluation [52].

Our study has several strengths. First, two experienced doctors performed detailed chart reviews to collect granular information rather than reliance on administrative data. Second, to our best knowledge, this is the first report where AKI in COVID-19 was defined strictly according to the KDIGO definition using both $\mathrm{SCr}$ and urine output criteria. Third, our analysis includes data on AKI prevalence and trajectories, including risk of progression to severe AKI. Fourth, with consent, data were collected from all critically ill patients who were admitted consecutively, reducing selection bias. Fifth, we emphasised on the impact of COVID-specific therapies on AKI 
risk in the analysis. Steroid use appeared to be protective. A follow-up analysis of data from subsequent waves when steroids were routinely prescribed will be informative. Lastly, we tracked and verified the primary outcome up to 3 months post-discharge, and where necessary, we contacted GPs to obtain SCr results post-discharge. This resulted in $87 \%$ availability of follow-up creatinine data and information about the risk of CKD after AKI.

Despite these strengths, we also acknowledge several limitations. First, this was a single-centre observational study which might impact the generalisation of findings. Second, due to the retrospective design, some laboratory results and 90-day $\mathrm{SCr}$ results were not available for all patients. We had incomplete information on fluid balance and diuretic use prior to ICU admission, especially since a third of patients were referrals from other institutions. Furthermore, we had no valid data on intravascular fluid status on admission to ICU which is a common problem in critical care settings. Third, urinalysis was not consistently performed in all patients. Fourth, true baseline $\mathrm{SCr}$ results were available in only $35 \%$. In the remaining cases, we used the $\mathrm{SCr}$ results on admission to hospital or a $\mathrm{SCr}$ estimate as the baseline value. Although this is in line with current recommendations [19], we acknowledge that this might have over- or underestimated the true incidence of AKI. Fifth, despite a detailed data collection, we may have missed some relevant nephrotoxic exposures that were not recorded in the medical notes, e.g. use of nephrotoxic drugs at the referring institutions. Sixth, as already mentioned, we judged renal recovery based on SCr results at hospital discharge, but acknowledge that this may have over-estimated kidney function. Although this is a common problem in patients with AKI, we acknowledge that muscle wasting has been reported as a particularly common problem in COVID19. Lastly, to date we have only follow-up SCr results up to 3 months. Data on kidney function beyond 3 months are not yet available.

\section{Conclusion}

Our analysis confirms a high incidence of AKI and AKI progression in critically ill COVID-19 patients during the first wave. Although 90-day dialysis independence appears to be high, long-term follow-up is needed to plan future crisis resource management and apply CKD progression prevention strategies. Future research should determine the impact of COVID-19-specific treatments on AKI prevention and progression [52].

\section{Abbreviations}

aHR: Adjusted hazard ratio; APACHE II: Acute Physiologic and Chronic Health Evaluation II; AKI: Acute kidney injury; CCl: Charlson Comorbidity Index; CFI: Clinical Frailty Scale; Cl: Confidence interval; CKD: Chronic kidney disease:
COVID-19: Coronavirus disease-19; CKRT: Continuous kidney replacement therapy; CRP: C-reactive protein; ECMO: Extracorporeal membrane oxygenation; HR: Hazard ratio; ICU: Intensive care unit; IHD: Intermittent hemodialysis; IQR: Interquartile range; KDIGO: Kidney Diseases: Improving Global Outcomes; KRT: Kidney replacement therapy; MAKE90: Major adverse kidney events at 90 days; MDRD: Modification of Diet in Renal Disease; PIKRT: Prolonged intermittent kidney replacement therapy; REC: Research Ethics Committee; RT-PCR: Reverse transcriptase-polymerase chain reaction; SCr: Serum creatinine; SD: Standard deviation; SOFA: Sequential Organ Failure Assessment; UK: United Kingdom.

\section{Supplementary Information}

The online version contains supplementary material available at https://doi. org/10.1186/s13613-021-00914-5.

Additional file 1. Additional Methods, Figure S1 and Tables S1-S8

\section{Acknowledgements}

The authors are grateful to all patients and their families who agreed to participate in this study. We would also like to thank Ursula Blanco and Tiago Soares for their contribution to data collection. Finally, we would like to thank all staff who looked after patients with COVID-19 in the expanded critical care unit and contributed to their recovery.

\section{Authors' contributions}

NL: conceptualisation, methodology, investigation, data collection, data interpretation, writing of first draft. EMC and WK: data collection, writing. LP and JG: data analysis, data interpretation, and writing. LC, KL, RL: data interpretation and revision. MO: conceptualisation, methodology, data interpretation, writing and revision. All authors provided critical revision of the manuscript. All authors read and approved the final manuscript.

\section{Funding}

This study received research support from Baxter and BioMérieux. The funders had no role in the design and conduct of the study; collection, management, analysis, and interpretation of the data; preparation, review, or approval of the manuscript; or the decision to submit the manuscript for publication.

\section{Availability of data and materials}

The datasets used and/or analysed during the current study are available from the corresponding author on reasonable request.

\section{Declarations}

Ethical approval and consent to participate

Ethical approval was obtained from the Health Research Authority and the Research Ethics Committee Health and Care Research Wales (REC Reference 20/WA/0175). Informed consent was obtained from the patients, personal, or professional consultee.

\section{Consent for publication}

Patients and/or legal representatives gave written consent to participating in the study and for their anonymous data to be included in publications.

\section{Competing interests}

All other authors declare no conflicts of interests.

\section{Author details}

1 'Department of Critical Care, Guy's \& St Thomas' Hospital NHS Foundation Hospital, 249 Westminster Bridge Road, London SE1 7EH, UK. ${ }^{2}$ Division of Nephrology and Excellence Centre for Critical Care Nephrology, King Chulalongkorn Memorial Hospital, Bangkok, Thailand. ${ }^{3}$ Critical Care Nephrology Research Unit, Chulalongkorn University, Bangkok, Thailand. ${ }^{4}$ Department of Medical Statistics, London School of Hygiene and Tropical Medicine, London, UK. 
Received: 16 June 2021 Accepted: 30 July 2021

Published online: 06 August 2021

\section{References}

1. Nadim MK, Forni LG, Mehta RL, Connor MJ, Liu KD, Ostermann M, et al. COVID-19-associated acute kidney injury: consensus report of the 25th Acute Disease Quality Initiative (ADQI) Workgroup. Nat Rev Nephrol. 2020;16(12):747-64.

2. Ostermann M, Lumlertgul N, Forni LG, Hoste E. What every Intensivist should know about COVID-19 associated acute kidney injury. J Crit Care. 2020;60:91-5.

3. Cheng Y, Luo R, Wang X, Wang K, Zhang N, Zhang M, et al. The incidence, risk factors, and prognosis of acute kidney injury in adult patients with coronavirus disease 2019. Clin J Am Soc Nephrol. 2020;15(10):1394-402.

4. Fisher M, Neugarten J, Bellin E, Yunes M, Stahl L, Johns TS, et al. AKI in hospitalized patients with and without COVID-19: a comparison study. J Am Soc Nephrol. 2020;31(9):2145-57.

5. Hirsch JS, Ng JH, Ross DW, Sharma P, Shah HH, Barnett RL, et al. Acute kidney injury in patients hospitalized with COVID-19. Kidney Int. 2020;98(1):209-18.

6. Rubin S, Orieux A, Prevel R, Garric A, Bats ML, Dabernat S, et al. Characterization of acute kidney injury in critically ill patients with severe coronavirus disease 2019. Clin Kidney J. 2020;13(3):354-61.

7. Yang X, Yu Y, Xu J, Shu H, Xia J, Liu H, et al. Clinical course and outcomes of critically ill patients with SARS-CoV-2 pneumonia in Wuhan, China: a single-centered, retrospective, observational study. Lancet Respir Med. 2020;8(5):475-81.

8. Xia P, Wen Y, Duan Y, Su H, Cao W, Xiao M, et al. Clinicopathological features and outcomes of acute kidney injury in critically III COVID-19 with prolonged disease course: a retrospective cohort. J Am Soc Nephrol. 2020:31(9):2205-21.

9. Xu J, Yang $X$, Yang L, Zou X, Wang Y, Wu Y, et al. Clinical course and predictors of 60-day mortality in 239 critically ill patients with COVID-19: a multicenter retrospective study from Wuhan, China. Crit Care. 2020;24(1):394.

10. Geri G, Darmon M, Zafrani L, Fartoukh M, Voiriot G, Le Marec J, et al. Acute kidney injury in SARS-CoV2-related pneumonia ICU patients: a retrospective multicenter study. Ann Intensive Care. 2021;11(1):86.

11. Gupta S, Coca SG, Chan L, Melamed ML, Brenner SK, Hayek SS, et al. AKI treated with renal replacement therapy in critically III patients with COVID-19. J Am Soc Nephrol. 2021:32(1):161-76.

12. Cheng Y, Luo R, Wang K, Zhang M, Wang Z, Dong L, et al. Kidney disease is associated with in-hospital death of patients with COVID-19. Kidney Int. 2020;97(5):829-38.

13. Wan YI, Bien Z, Apea VJ, Orkin CM, Dhairyawan R, Kirwan CJ, et al. Acute Kidney Injury in COVID-19: multicentre prospective analysis of registry data. Clin Kidney J. 2021. https://doi.org/10.1093/ckj/sfab071.

14. Martínez-Rueda AJ, Álvarez RD, Méndez-Pérez RA, Fernández-Camargo DA, Gaytan-Arocha JE, Berman-Parks N, et al. Community- and hospitalacquired acute kidney injury in COVID-19: different phenotypes and dismal prognosis. Blood Purif. 2021. https://doi.org/10.1159/000513948.

15. ICNARC report on COVID-19 in critical care. 2021. Available at https:// www.icnarc.org/Our-Audit/Audits/Cmp/Reports. Accessed 27 July 2021

16. Doidge JC, Gould DW, Ferrando-Vivas P, Mouncey PR, Thomas K, Shankar-Hari M, et al. Trends in intensive care for patients with COVID-19 in England, Wales, and Northern Ireland. Am J Respir Crit Care Med. 2021;203(5):565-74.

17. Lumlertgul $N$, Tunstell $P$, Watts $C$, Hanks F, Cameron L, Tovey L, et al. Inhouse production of dialysis solutions to overcome challenges during the coronavirus disease 2019 pandemic. Kidney Int Rep. 2021;6(1):200-6.

18. Fisher R, Clarke J, Al-Arfi K, Saha R, Lioudaki E, Mehta R, et al. Provision of acute renal replacement therapy, using three separate modalities, in critically ill patients during the COVID-19 pandemic. An after action review from a UK tertiary critical care centre. J Crit Care. 2021;62:190-6.

19. Khwaja A. KDIGO clinical practice guidelines for acute kidney injury. Nephron Clin Pract. 2012;120(4):c179-184.

20. Katayama S, Koyama K, Goto Y, Koinuma T, Tonai K, Shima J, et al. Body weight definitions for evaluating a urinary diagnosis of acute kidney injury in patients with sepsis. BMC Nephrol. 2018;19(1):101.
21. Peng S, Wang HY, Sun X, Li P, Ye Z, Li Q, et al. Early versus late acute kidney injury among patients with COVID-19-a multicenter study from Wuhan. China Nephrol Dial Transplant. 2020;35(12):2095-102.

22. Chawla LS, Bellomo R, Bihorac A, Goldstein SL, Siew ED, Bagshaw SM, et al. Acute kidney disease and renal recovery: consensus report of the Acute Disease Quality Initiative (ADQI) 16 Workgroup. Nat Rev Nephrol. 2017;13(4):241-57.

23. Chand S, Kapoor S, Orsi D, Fazzari MJ, Tanner TG, Umeh GC, et al. COVID19-associated critical illness-report of the first 300 patients admitted to intensive care units at a New York City Medical Center. J Intensive Care Med. 2020;35(10):963-70.

24. Flythe JE, Assimon MM, Tugman MJ, Chang EH, Gupta S, Shah J, et al. Characteristics and outcomes of individuals with pre-existing kidney disease and COVID-19 admitted to intensive care units in the United States. Am J Kidney Dis. 2021;77(2):190-203.e191.

25. Cummings MJ, Baldwin MR, Abrams D, Jacobson SD, Meyer BJ, Balough EM, et al. Epidemiology, clinical course, and outcomes of critically ill adults with COVID-19 in New York City: a prospective cohort study. Lancet. 2020;395(10239):1763-70.

26. Zhou S, Yang Y, Zhang X, Li Z, Liu X, Hu C, et al. Clinical course of 195 critically ill COVID-19 patients: a retrospective multicenter study. Shock. 2020;54(5):644-51.

27. Cheng Y, Zhang N, Luo R, Zhang M, Wang Z, Dong L, et al. Risk factors and outcomes of acute kidney injury in critically ill patients with coronavirus disease 2019. Kidney Dis (Basel). 2021;7(2):111-9.

28. Hardenberg JB, Stockmann H, Aigner A, Gotthardt I, Enghard P, Hinze $\mathrm{C}$, et al. Critical illness and systemic inflammation are key risk factors of severe acute kidney injury in patients with COVID-19. Kidney Int Rep. 2021:6(4):905-15.

29. Piñeiro GJ, Molina-Andújar A, Hermida E, Blasco M, Quintana LF, Rojas GM, et al. Severe acute kidney injury in critically ill COVID-19 patients. J Nephrol. 2021;34:285-93.

30. Ostermann M, Liu K, Kashani K. Fluid management in acute kidney injury. Chest. 2019;156(3):594-603.

31. Zhang J, Crichton S, Dixon A, Seylanova N, Peng ZY, Ostermann M. Cumulative fluid accumulation is associated with the development of acute kidney injury and non-recovery of renal function: a retrospective analysis. Crit Care. 2019;23(1):392.

32. Ostermann M, Straaten HM, Forni LG. Fluid overload and acute kidney injury: cause or consequence? Crit Care. 2015;19:443.

33. Wang F, Ran L, Qian C, Hua J, Luo Z, Ding M, et al. Epidemiology and outcomes of acute kidney injury in COVID-19 patients with acute respiratory distress syndrome: a multicenter retrospective study. Blood Purif. 2020;50:499.

34. Doher MP, Torres de Carvalho FR, Scherer PF, Matsui TN, Ammirati AL, Caldin da Silva B, et al. Acute kidney injury and renal replacement therapy in critically ill COVID-19 patients: risk factors and outcomes: a single-center experience in Brazil. Blood Purif. 2020;50:520-30.

35. Casas-Aparicio GA, León-Rodríguez I, Alvarado-de la Barrera C, González-Navarro M, Peralta-Prado AB, Luna-Villalobos Y, et al. Acute kidney injury in patients with severe COVID-19 in Mexico. PLoS ONE. 2021;16(2):e0246595

36. Pei G, Zhang Z, Peng J, Liu L, Zhang C, Yu C, et al. Renal involvement and early prognosis in patients with COVID-19 pneumonia. J Am Soc Nephrol. 2020;31(6):1157-65.

37. Angus DC, Derde L, Al-Beidh F, Annane D, Arabi Y, Beane A, et al. Effect of hydrocortisone on mortality and organ support in patients with severe COVID-19: the REMAP-CAP COVID-19 corticosteroid domain randomized clinical trial. JAMA. 2020;324(13):1317-29.

38. Horby P, Lim WS, Emberson JR, Mafham M, Bell JL, Linsell L, et al. Dexamethasone in hospitalized patients with Covid-19. N Engl J Med. 2021:384(8):693-704.

39. Alhazzani W, Evans L, Alshamsi F, Møller MH, Ostermann M, Prescott HC, et al. Surviving sepsis campaign guidelines on the management of adults with coronavirus disease 2019 (COVID-19) in the ICU: first update. Crit Care Med. 2021:49(3):e219-34.

40. Wu C, Chen X, Cai Y, Xia J, Zhou X, Xu S, et al. Risk factors associated with acute respiratory distress syndrome and death in patients with coronavirus disease 2019 pneumonia in Wuhan. China JAMA Intern Med. 2020;180(7):934-43. 
41. Sang L, Chen S, Zheng X, Guan W, Zhang Z, Liang W, et al. The incidence, risk factors and prognosis of acute kidney injury in severe and critically ill patients with COVID-19 in mainland China: a retrospective study. BMC Pulm Med. 2020;20(1):290.

42. $\mathrm{Ng} \mathrm{JH}$, Hirsch JS, Hazzan A, Wanchoo R, Shah HH, Malieckal DA, et al. Outcomes among patients hospitalized with COVID-19 and acute kidney injury. Am J Kidney Dis. 2021;77(2):204-215.e201.

43. Lowe R, Ferrari M, Nasim-Mohi M, Jackson A, Beecham R, Veighey K, et al. Clinical characteristics and outcome of critically ill COVID-19 patients with acute kidney injury: a single centre cohort study. BMC Nephrol. 2021;22(1):92.

44. Stevens JS, King KL, Robbins-Juarez SY, Khairallah P, Toma K, Alvarado Verduzco H, et al. High rate of renal recovery in survivors of COVID-19 associated acute renal failure requiring renal replacement therapy. PLoS ONE. 2020;15(12):e0244131.

45. Stockmann H, Hardenberg JB, Aigner A, Hinze C, Gotthardt I, Stier B, et al. High rates of long-term renal recovery in survivors of coronavirus disease 2019-associated acute kidney injury requiring kidney replacement therapy. Kidney Int. 2021;99(4):1021-2.

46. Eriksson KE, Campoccia-Jalde F, Rysz S, Rimes-Stigare C. Continuous renal replacement therapy in intensive care patients with COVID-19; survival and renal recovery. J Crit Care. 2021;64:125-30.

47. Prowle JR, Kolic I, Purdell-Lewis J, Taylor R, Pearse RM, Kirwan CJ. Serum creatinine changes associated with critical illness and detection of persistent renal dysfunction after AKI. Clin J Am Soc Nephrol. 2014;9(6):1015-23.

48. Kashani K, Rosner MH, Ostermann M. Creatinine: from physiology to clinical application. Eur J Intern Med. 2020;72:9-14.

49. Hultström M, Lipcsey M, Wallin E, Larsson IM, Larsson A, Frithiof R. Severe acute kidney injury associated with progression of chronic kidney disease after critical COVID-19. Crit Care. 2021;25(1):37.

50. Nugent J, Aklilu A, Yamamoto Y, Simonov M, Li F, Biswas A, et al. Assessment of acute kidney injury and longitudinal kidney function after hospital discharge among patients with and without COVID-19. JAMA Netw Open. 2021;4(3):e211095.

51. Haines RW, Powell-Tuck J, Leonard H, Crichton S, Ostermann M. Longterm kidney function of patients discharged from hospital after an intensive care admission: observational cohort study. Sci Rep. 2021;11(1):9928.

52. Ostermann M, Bellomo R, Burdmann EA, Doi K, Endre ZH, Goldstein SL, et al. Controversies in acute kidney injury: conclusions from a kidney disease: improving global outcomes (KDIGO) conference. Kidney Int. 2020;98(2):294-309.

\section{Publisher's Note}

Springer Nature remains neutral with regard to jurisdictional claims in published maps and institutional affiliations.

\section{Submit your manuscript to a SpringerOpen ${ }^{\circ}$ journal and benefit from:}

- Convenient online submission

- Rigorous peer review

- Open access: articles freely available online

- High visibility within the field

- Retaining the copyright to your article

Submit your next manuscript at $\boldsymbol{\text { springeropen.com }}$ 